\title{
Serotonin in Autism AND Pediatric Epilepsies
}

\author{
Diane C. Chugani* \\ Departments of Pediatrics and Radiology, Children's Hospital of Michigan, Detroit Medical Center, \\ Wayne State University School of Medicine, Detroit, Michigan
}

Serotonergic abnormalities have been reported in both autism and epilepsy. This association may provide insights into underlying mechanisms of these disorders because serotonin plays an important neurotrophic role during brain development-and there is evidence for abnormal cortical development in both autism and some forms of epilepsy. This review explores the hypothesis that an early disturbance in the serotonin system affects cortical development and the development of thalamocortical innervation, and is a potential mechanism, common to autism and pediatric epilepsies associated with cortical dysplasia. An argument is made that cortical malformation leads to abnormalities of thalamocortical connectivity, and that serotonin plays a critical role in this process. Finally, a role for altered metabolism of the serotonin precursur, tryptophan, in both epilepsy and autism is discussed.

MRDD Research Reviews 2004;10:112-116.

Key Words: serotonin; autism; epilepsy; tryptophan; cortical development; kynurenine

$\mathrm{E}$ pilepsy is more common among autistic children than in the general population; conversely, autism (or milder pervasive developmental disorders) is more common in epileptic children than in the general population. There is evidence for abnormalities of the neurotransmitter serotonin in both epilepsy and autism. The role of serotonin in brain development is briefly reviewed here and then the evidence considered for a role of an altered serotonin system in these developmental disorders. We hypothesize that serotonergic abnormalities during prenatal and early postnatal development may lead to changes in thalamocortical connectivity, which results in a predisposition for autism and epilepsy. In addition, we discuss the involvement of aberrant metabolism of tryptophan-the metabolic precursor of serotonin-as a potential mechanism for alterations in serotonin availability.

\section{ALTERED PRENATAL SEROTONIN-EVIDENCE FOR A ROLE IN AUTISM}

Abnormalities of serotonergic function associated with autism were first proposed when Schain and Freedman [1961] reported hyperserotonemia in autistic and mentally retarded children. This result has been replicated by several groups [Hoshino et al., 1984; Anderson et al., 1987; Cook et al., 1990], and extended with the recognition that blood serotonin is also elevated in the first degree relatives of these children [Leventhal et al., 1990; Piven et al., 1999; Cook et al., 1994; Leboyer et al.,
1999]. How the abnormalities of blood serotonin might be related to brain serotonin, however, is not well understood.

Several recent studies have reported associations of gene dysfunction that may impact serotonin metabolism in autism. For example, our group has found a susceptibility mutation in a promoter variant of the tryptophan 2,3-dioxygenase gene [Nabi et al., 2004]. Tryptophan 2,3-dioxygenase is a rate-limiting enzyme in the metabolism of tryptophan by the kynurenine pathway. A mutation that results in decreased activity of this enzyme could decrease the metabolism of tryptophan through the kynurenine pathway, causing a shift toward increased levels of serotonin. Interestingly, tryptophan 2,3-dioxygenase, as well as indoleamine 2,3-dioxygenase (which also catalyses tryptophan metabolism by the kynurenine pathway), are expressed in the placenta and have a role in the prevention of allogeneic rejection of the fetus [Munn et al., 1998; Suzuki et al., 2001].

Another recent study investigated the relationship of maternal genotypes for monoamine oxidase-A (MAO-A), an enzyme that metabolizes serotonin, with the susceptibility of autism in their offspring. Jones et al. [2004] reported that maternal genotypes containing specific polymorphisms at the MAO-A locus showed significant negative correlations with the intelligence quotient (IQ) in children with autism. These results are consistent with those of Cohen et al. [2003], who found that a low-activity MAO-A allele (due to an upstream variable-number tandem repeat region) is associated with both lower IQ and more severe autistic behavior in children, as compared to the high-activity allele.

In addition, the serotonin transporter is highly expressed in the brush border membrane of the human placenta and may mediate transport of serotonin from the maternal circulation to the developing fetus [Balkovetz et al., 1989]. Efforts to relate increased blood serotonin to polymorphisms of the serotonin transporter have been largely unsuccessful, although a small effect on blood serotonin has not been ruled out [Persico et al., 2000; Anderson et al., 2002; Persico et al., 2002; Betancur et al., 2002]. Given that there is expression of the serotonin transporter

*Correspondence to: Diane C. Chugani, Ph.D., Children's Hospital of Michigan, PET Center, 3901 Beaubien Blvd., Detroit, MI 48201. E-mail: dchugani@pet.wayne.edu Received 23 June 2004; Accepted 25 June 2004

Published online in Wiley InterScience (www.interscience.wiley.com).

DOI: $10.1002 / \mathrm{mrdd} .20021$ 
in the placenta, a maternal modifier effect of the serotonin transporter might constitute a risk factor for autism.

These observations have led to the view that alterations of serotonin (or tryptophan) metabolism and/or transport during prenatal development may regulate key steps during cortical development. Such a view is supported by recent evidence showing that abnormal serotonin levels in the brain may alter prenatal cortical development. Rakic and colleagues have demonstrated that serotonergic fibers innervate Cajal Retzius cells, which are necessary for cortical column development [Janusonis et al., 2004]. Furthermore, these investigators showed that treatment with the serotonin agonist 5-methoxytryptamine during fetal development led to alterations in brain reelin levels (a glycoprotein produced by Cajal Retzius cells) and abnormalities of presubicular cortical column development. These results are extremely provocative because both abnormal levels of reelin [Fatemi et al., 2001] and abnormalities in cortical columns [Casanova et al., 2002a, 2002b] have been demonstrated in human autism autopsy brain tissue. In particular, Casanova et al. [2002a, 2002b] reported that there was an increased number of minicolumns, combined with fewer cells per column or greater cell dispersion, in autism brain samples compared to age-matched controls.

\section{BRAIN SEROTONIN IN AUTISTIC CHILDREN}

To determine whether there are serotonergic abnormalities in the brains of children with autism, we have evaluated serotonin synthesis capacity in vivo with positron emission tomography (PET), using the tryptophan analog alpha $\left[{ }^{11} \mathrm{C}\right]$ methyl-L-tryptophan (AMT) as a tracer. AMT, developed as a PET tracer for serotonin synthesis [Diksic et al., 1991; Muzik et al., 1997; Chugani et al., 1998a], is an analog of tryptophan, the precursor for serotonin. We have examined this tracer in a study of autistic and nonautistic children. Our studies illustrated two fundamentally different types of serotonergic abnormalities in autistic children [Chugani et al., 1997, 1999]. The first is a difference in the change with age in whole brain serotonin synthesis. Global brain values for serotonin synthesis capacity were obtained for 30 healthy seizure-free autistic children, for 8 of their healthy nonautistic siblings, and for 16 epileptic children without autism. For nonautistic children (with or without epilepsy), serotonin synthesis ca- pacity was $>200 \%$ of adult values until the age of 5 years and then declined toward adult values. In autistic children, serotonin synthesis capacity increased gradually between the ages of 2 years and 15 years to values 1.5 times the adult normal values. In other words, at a given early age less than 5 years, the serotonin synthesis capacity in an autistic child is much lower than that in a nonautistic child. These data suggest that in human brain, there is a period of high brain serotonin synthesis capacity during early childhood and that this developmental process is disrupted in autistic children.

The second type of abnormality relates to focal abnormalities in brain serotonin synthesis. Asymmetries of AMT uptake in frontal cortex, thalamus, and cerebellum were visualized in a small sample of children with autism [Chugani et al., 1997]. In a larger group of autistic children, we have shown that subgroups of autistic children can be defined by presence or absence, and side of cortical asymmetry, in AMT abnormalities; these subgroups differed on measures of language and handedness. Autistic children with left cortical AMT decreases showed a higher prevalence of severe language impairment, whereas those with right cortical decreases showed a higher prevalence of left- and mixed-handedness (Chandana et al., in press).

In the normal human brain, there are significant differences in minicolumn organization between the left and right sides [for review, see Hutsler and Galuske, 2003]. These differences suggest that alterations in minicolumn organization-in autism-may have a profound impact on hemispheric specialization and functions that dependent on hemispheric specialization (such as language). In normal brain, the width of minicolumns and the distance between the columns is larger on the left than on the right [Seldon, 1981a, 1981b, 1982; Buxhoeveden et al., 2001]. Seldon [1981a, 1981b, 1982] also showed that pyramidal cells in the posterior language cortex on the left contacted fewer columnar units than on the right. In addition, there is asymmetry in the size of the pyramidal cells constituting the minicolumns, with a greater number of large pyramidal cells in the left hemisphere than in the right hemisphere [Hutsler, 2003]. As a consequence of these differences, pyramidal cells in the left hemisphere contact fewer adjacent minicolumns than pyramidal cells in the right hemisphere. Conversely, macrocolumns appear not to be asymmetric in size, although the distance between macrocolumns has been reported to be $20 \%$ greater on left than on the right in Brodmann area 22 [Galuske et al., 2000].

The serotonin transporter is transiently expressed by glutamatergic thalamocortical afferents [D'Amato et al., 1987; Bennett-Clarke et al., 1996; Lebrand et al., 1996] during the first 2 postnatal weeks in rodents. Postnatal serotonin levels regulate the size of cortical barrel macrocolumns: too little serotonin leads to smaller barrel macrocolumns and too much serotonin leads to larger barrels. Depletion of serotonin during the postnatal period delays the development of the barrel fields of the rat somatosensory cortex [Blue et al., 1991; OsterheldHaas et al., 1994] and decreases the size of the barrel fields [Bennett-Clarke et al., 1994]. In contrast, increased serotonin brain levels during this critical period, as in the MAO-A knockout mouse or serotonin transporter knockout mouse [Salichon et al., 2001], results in increased tangential arborization of thalamocortical axons, resulting in blurring of the boundaries of the cortical barrels [Cases et al., 1996]. We propose that the presence of smaller, more closely spaced minicolumns in the brains of autistic children [Casanova et al., 2002a, 2002b] might trigger compensatory changes in cortical serotonin synthesis in the early postnatal period when serotonin regulates formation of thalamocortical afferents. For example, decreased serotonin might normalize the number of minicolumns per macrocolumn innervated by a given set of thalamocortical afferents by decreasing thalamocortical axon arborization.

\section{EVIDENCE FOR ROLE OF SEROTONIN IN EPILEPSY}

Although in adults the predominant form of epilepsy involves medial temporal lobe structures, epilepsy in young children is most commonly associated with focal or diffuse cortical malformations [Kuzniecky and Barkovich, 2001]. There are many lines of evidence implicating serotonergic mechanisms as playing a role in epileptogenesis in both humans and animals [reviewed in Toczek et al., 2003; Teskey et al., 2004]. In human brain tissue surgically removed for seizure control, levels of 5-HIAA (5-hydroxyindole acetic acid, the breakdown product of serotonin) were found to be higher in actively spiking temporal cortex, as compared to normal controls [Louw et al., 1989; Pintor et al., 1990]. Increased serotonin immunoreactivity has also been reported in human epileptic brain tissue resected for the control of epilepsy [Trottier et al., 1996]. Interestingly, the increase in serotonin immuno- 
reactivity was seen in "fine, wispy fibers" characteristic of the pattern of staining of thalamocortical fibers expressing serotonin transporters during development, rather than the "beads on a string" staining typical of raphe-cortical serotonergic fibers. In a study that compared epilepsy patients with cortical dysplasia with patients showing normal imaging characteristics, Fedi et al. [2001] reported increased AMT uptake in $60 \%$ of the patients with cortical dysplasia but only $30 \%$ of patients with normal MRIs. Juhasz et al. [2003] demonstrated that objectively identified cortical areas of increased AMT uptake (PET studies) were highly specific for the lobe of seizure onset, both in patients with normal MRI and in those with developmental cortical malformations. Interestingly, the spatial comparison of AMT PET abnormalities with intracranial EEG recordings demonstrated that cortex adjacent to the region showing increased AMT uptake is most often the site of seizure onset, although parts of the region with increased AMT uptake itself were also commonly epileptogenic.

This epileptogenic pattern is similar to that reported for the microgyrus lesion model in the rat, in which focal cortical lesions are produced by freezing a small cortical region on postnatal day 0 or 1 [Dvorak and Feit, 1977]. Dvorak and Feit [1977] showed that a freeze lesion in the neonatal period kills most of the neurons present at the time of the lesion. For a lesion on postnatal day 1 , neurons in cortical layers IV and $\mathrm{V}$ are destroyed resulting in a four-layer cortex. For lesions on postnatal day 0 , layer IV neurons are spared leading to less retargeting of thalamocortical afferents [Jacobs et al., 1999]. Microelectrode recordings show that epileptiform activity arises from the adjacent normal appearing cortex, and this epileptiform activity is sustained even if it is surgically separated from the focal lesion [Jacobs et al., 1999]. This finding has led to the hypothesis that the epileptiform activity results from reorganization of afferent inputs, where adjacent normal cortex is hyperinnervated due to lack of appropriate target neurons in the lesion. Indeed, Rosen et al. [2000] have shown that cortical lesions result not only in increased thalamic innervation of cortex adjacent to the microgyrus caused by freeze lesion in the neonatal period, but also in changes in corticothalamic and callosal efferents to homotopic cortical regions from the perilesional region.

As discussed above, thalamocortical afferent fibers contain serotonin during development due to transient expres- sion of the serotonin transporter [Bennett-Clarke et al., 1996; Lebrand et al., 1996]. We hypothesize that these fibers continue to express the transporter in tissue with cortical dysplasia rather than down-regulating the serotonin transporter with brain development. Such a developmental abnormality would be consistent with the report of increased immunoreactivity of fine fibers (presumably thalamocortical) by Trottier et al., [1996] in the epileptic cortex. These fibers tend to concentrate at the edge of cortical dysplasias, perhaps due to lack of proper targets within the dysplastic tissue.

Teskey et al. [2004] have recently reported that $\mathrm{MAO}-\mathrm{A}$ knockout mice are more susceptible than wild-type mice to seizures induced by electrical and pentylenetetrazol kindling. As discussed above, thalamocortical innervation of the cortex is profoundly affected in the MAO-A knockout mouse. MAO knockout mice show shorter latency to the onset of the first seizure, but shorter total duration of seizures and fewer seizures per day. Thus, these authors conclude that the MAO-A knockout mice have a lower seizure threshold, but a relative resistance to epileptogenesis. They hypothesized that the shorter latency to the first seizure is due to changes in brain organization, a consequence of elevated serotonin during development; the resistance to epileptogenesis is attributed to the persistent high levels of serotonin in the adult animals.

Increased serotonin synthesis, as evidenced by increased AMT uptake adjacent to the seizure focus, might also be related to sprouting of raphe-cortical serotonergic fibers due to release of brainderived neurotrophic factor (BDNF) from the active epileptic focus. BDNF mRNA and protein are increased in the seizure focus following seizures in epilepsy patients as well as in a number of epilepsy animal models [for review, see Binder et al., 2001]. Infusion of BDNF into rat brain increases sprouting of serotonergic fibers [Mamounas et al., 2000], suggesting that the increased AMT uptake adjacent to the focus may be the result of serotonergic fiber sprouting induced by BDNF. Support for this type of mechanism has been obtained in studies of adult temporal lobe epilepsy (TLE). Natsume et al. [2003] reported increased AMT uptake in the hippocampus ipsilateral to the focus of TLE patients with normal hippocampal volumes but not in patients with hippocampal atrophy. These data may be relevant to seizureinduced neurogenesis [Parent, 2002] be- cause there is evidence that serotonin is a regulator of neurogenesis in the dentate gyrus [Gould, 1999]. Speculatively, increased neurogenesis in the patients showing increased AMT uptake in hippocampus may account for the normal hippocampal volume in these patients.

Increased uptake of AMT in epilepsy patients may also reflect tryptophan metabolism via the kynurenine pathway in the brain. Under normal circumstances, the concentration of tryptophan metabolites of this pathway are between 100- and 1000-fold lower than the concentration of tryptophan in the brain [Saito et al., 1993]. In comparison, the sum of the concentrations of serotonin and its metabolite 5-HIAA is approximately one-fifth the concentration of tryptophan in brain [Hery et al., 1977]. Therefore, the kynurenine pathways are not expected to contribute significantly to the accumulation of AMT in brain under normal circumstances. However, following brain injury or immune activation, there is induction of indoleamine 2,3-dioxygenase [Saito et al., 1993], leading to a significant increase of kynurenine pathway metabolites. Several metabolites of the kynurenine pathway-quinolinic acid, kynurenine, and 3-hydroxykynurenine- - are convulsants through their action as agonists at N-methyl-D-aspartate (NMDA) receptors [Perkins and Stone, 1982, 1983; Vezzani et al., 1985; Lapin, 1978, 1980, 1982]. Kynurenic acid, however, which is another metabolite in this pathway and is an NMDA antagonist [Perkins and Stone, 1982], has been reported to suppress epileptiform activity in animal models of epilepsy [Sharfman and Ofer, 1997]. It has been postulated that metabolites of the kynurenine pathway might play a role in the initiation and maintenance of seizures in human seizure disorders [Feldblum et al., 1988; Heyes et al., 1990]. Quinolinic acid concentrations are apparently not increased in the seizure focus as compared to nonfocus brain regions from adults undergoing surgery for temporal lobe epilepsy [Heyes et al., 1990]. However, we have demonstrated in patients with tuberous sclerosis 5-fold higher concentrations of quinolinic acid in tubers that also show elevated AMT accumulation (i.e., epileptogenic tubers) compared to tubers and brain tissue that show no elevated AMT accumulation [Chugani et al., 1998b]. These findings suggest that, in at least some cases, the mechanism of epileptogenesis may involve activation of the kynurenine pathway, leading to the production of endogenous convulsants. Furthermore, induction of this pathway may 
also result in altered availability of tryptophan for serotonin synthesis.

\section{CONCLUSION}

We have reviewed a number of studies that indicate that serotonergic abnormalities are associated with abnormalities of cortical development and thalamocortical connectivity and propose that these serotonin-linked abnormalities are common mechanistic features of autism and epilepsy. Abnormal serotonin transport or synthesis during brain development may directly affect formation of intracortical and thalamocortical circuitry. The relative balance of tryptophan metabolism, regulated by the serotonin and kynurenine pathways, may also be important in both disorders. These serotonergic abnormalities may at least partially explain why autism and epilepsy are commonly associated.

\section{ACKNOWLEDGMENT}

This work was supported in part by NIH Grants HD34942, NS 38324, and NS 45151. I thank Dr. Csaba Juhasz for reviewing the article.

\section{REFERENCES}

Anderson GM, Freedman DX, Cohen DJ, Volkmar FR, Hoder EL, McPhedran P, Minderaa RB, Hansen CR, Young JG. 1987. Whole blood serotonin in autistic and normal subjects. J Child Psychol Psychiatr 28(6):885900 .

Anderson GM, Gutknecht L, Cohen DJ, BraillyTabard S, Cohen JH, Ferrari P, Roubertoux PL, Tordjman S. 2002. Serotonin transporter promoter variants in autism: functional effects and relationship to platelet hyperserotonemia. Mol Psychiatr 7(8):831-836.

Balkovetz DF, Tiruppathi C, Leibach FH, Mahesh VB, Ganapathy V. 1989. Evidence for an imipramine-sensitive serotonin transporter in human placental brush-border membranes. J Biol Chem 264(4):2195-2198.

Bennett-Clarke CA, Leslie MJ, Lane RD, Rhoades RW. 1994. Effect of serotonin depletion on vibrissae-related patterns in the rat's somatosensory cortex. J Neurosci 14:7594-7607.

Bennett-Clark CA, Chiaia NL, Rhoades RW. 1996. Thalamocortical afferents in rat transiently express high-affinity serotonin uptake sites. Brain Res 733:301-306.

Betancur C, Corbex M, Spielewoy C, Philippe A, Laplanche JL, Launay JM, Gillberg C, Mouren-Simeoni MC, Hamon M, Giros B, Nosten-Bertrand M, Leboyer M. 2002. Serotonin transporter gene polymorphisms and hyperserotonemia in autistic disorder. Mol Psychiatr 7(1):67-71.

Binder DK, Croll SD, Gall CM, Scharfman HE. 2001. BDNF and epilepsy: too much of a good thing?. Trends Neurosci. 24:47-53.

Blue ME, Erzurumlu RS, Jhaveri S. 1991. A comparison of pattern formation by thalamocortical and serotonergic afferents in the rat barrel field cortex. Cerebral Cortex 1:380-389.

Buxhoeveden DP, Switala AE, Litaker M, Roy E, Casanova MF. 2001. Lateralization of minicolumns in human planum temporale is ab- sent in nonhuman primate cortex. Brain $\mathrm{Be}-$ hav Evol 57:349-358.

Casanova MF, Buxhoeveden DP, Brown C. 2002a. Clinical and macroscopic correlates of minicolumnar pathology in autism. J Child Neurol 17:692-695.

Casanova MF, Buxhoeveden DP, Switala AE, Roy E. 2002b. Minicolumnar pathology in autism. Neurology 58:428-432.

Cases O, Vitalis T, Seif I, De Maeyer E, Sotelo C, Gaspar P. 1996. Lack of barrels in the somatosensory cortex of monoamine oxidase A-deficient mice: role of a serotonin excess during the critical period. Neuron 16:297-307.

Chandana SR, Behen ME, Juhász C, Muzik O, Rothermel RD, Thomas J. Mangner TJ, Chakraborty PK, Harry T. Chugani HT, Chugani DC. Significance of abnormalities in developmental trajectory and asymmetry of cortical serotonin synthesis in autism. Int J Dev Neurosci (in press).

Chugani, D.C., Muzik, O., Rothermel, R., Behen, M., Chakraborty, P., Mangner, T., da Silva, E.A. and Chugani, H.T. 1997. Altered serotonin synthesis in the dentatothalamocortical pathway in autistic boys. Ann Neurol 42: 666-669.

Chugani DC, Muzik O, Chakraborty P, Mangner T, Chugani HT. 1998a. Human brain serotonin synthesis capacity measured in vivo with alpha-[C-11]methyl-L-tryptophan. Synapse 28(1):33-43.

Chugani DC, Heyes MP, Kuhn DM, Chugani HT 1998b. Evidence that $\alpha[\mathrm{C}-11]$ methyl-L-tryptophan PET traces tryptophan metabolism via the kynurenine pathway in tuberous sclerosis complex. Soc Neurosci Abstr 24:1757.

Chugani DC, Muzik O, Behen M, Rothermel R, Janisse JJ, Lee J, Chugani HT. 1999. Developmental changes in brain serotonin synthesis capacity in autistic and nonautistic children. Ann Neurol 45:287-295.

Cohen IL, Liu X, Schutz C, White BN, Jenkins EC, Brown WT, Holden JJ. 2003. Association of autism severity with a monoamine oxidase A functional polymorphism. Clin Genet 64(3):190-197.

Cook EH Jr, Leventhal BL, Heller W, Metz J, Wainwright M, Freedman DX. 1990. Autistic children and their first-degree relatives: relationships between serotonin and norepinephrine levels and intelligence. J Neuropsychiatr Clin Neurosci 2(3):268-274.

Cook EH Jr, Charak DA, Arida J, Spohn JA, Roizen NJ, Leventhal BL. 1994. Depressive and obsessive-compulsive symptoms in hyperserotonemic parents of children with autistic disorder. Psychiatr Res 52(1):25-33.

D'Amato RJ, Blue ME, Largent BL, Lynch DR, Ledbetter DJ, Molliver ME, Snyder SH. 1987. Ontogeny of the serotonergic projection to rat neocortex: transient expression of a dense innervation to primary sensory areas. Proc Natl Acad Sci USA 84:4322-4326.

Diksic M, Nagahiro S, Chaly T, Sourkes TL, Yamamoto YL, Feindel W. 1991. Serotonin synthesis rate measured in living dog brain by positron emission tomography. J Neurochem 56:153-162.

Dvorak K, Feit J. 1977. Migration of neuroblasts through partial necrosis of the cerebral cortex in newborn rats: Contribution to the problems of orphological development and developmental period of cerebral microgyria. Acta Neruopathol 38:203-212.

Fatemi SH, Stary JM, Halt AR, Realmuto GR. 2001. Dysregulation of Reelin and Bcl-2 proteins in autistic cerebellum. J Autism Dev Disorders 31(6):529-535.
Fedi M, Reutens D, Okazawa H, Andermann F, Boling W, Dubeau F, White C, Nakai A, Gross DW, Andermann E, Diksic M. 2001. Localizing value of alpha-methyl-L-tryptophan PET in intractable epilepsy of neocortical origin. Neurology 57:1629-1636.

Feldblum S, Rougier A, Loiseau H, et al. 1988. Quinolinic acid phosphoribosyl transferase activity is decreased in epileptic human brain tissue. Epilepsia 29:523-529.

Galuske RA, Schlote W, Bratzke H, Singer W 2000. Interhemispheric asymmetries of the modular structure in human temporal cortex. Science 289:1946-1949

Gould E. 1999. Serotonin and hippocampal neurogenesis. Neuropsychopharmacology 21(Suppl): 46S-51S.

Hery F, Chouvet G, Kan JP, et al. 1977. Daily variations of various parameters of serotonin metabolism in the rat brain. II. Circadian variations in serum and cerebral tryptophan levels: lack of correlations with 5-HT turnover. Brain Res 123:137-145.

Heyes MP, Wyler AR, Devinsky O, et al. 1990. Quinolinic acid concentrations in brain and cerebrospinal fluid of patients with intractable complex partial seizures. Epilepsia 31:172177.

Hoshino Y, Yamamoto T, Kaneko M, Tachibana R, Watanabe M, Ono Y, Kumashiro $\mathrm{H}$. 1984. Blood serotonin and free tryptophan concentration in autistic children. Neuropsychobiology 11(1):22-27

Hutsler JJ. 2003. The specialized structure of human language cortex: pyramidal cell size asymmetries within auditory and languageassociated regions of the temporal lobes. Brain \& Language 86:226-242.

Hutsler J, Galuske RAW. 2003. Hemispheric asymmetries in cerebral cortical networks. Trends Neurosci 26:429-435.

Janusonis S, Gluncic V, Rakic P. 2004. Early serotonergic projections to Cajal-Retzius cells: Relevance for cortical development. J Neurosci 24:1652-1659.

Jacobs KM, Hwang BJ, Prince DA. 1999. Focal epileptogenesis in a rat model of polymicrogyria. J Neurophysiol 81:159-173.

Jones MB, Palmour RM, Zwaigenbaum L, Szatmari P. 2004. Modifier effects in autism at the MAO-A and DBH loci. Am J Med Genet B 126 (1):58-65.

Juhasz C, Chugani DC, Muzik O, Shah A, Asano E, Mangner TJ, Chakraborty PK, Sood S, Chugani HT. 2003. Alpha-methyl-L-tryptophan PET detects epileptogenic cortex in children with intractable epilepsy. Neurology 60:960-968.

Kuzniecky RI, Barkovich AJ. 2001. Malformations of cortical development and epilepsy. Brain Dev 23(1):2-11.

Lapin IP. 1978. Stimulant and convulsant effects of kynurenines injected into brain ventricles in mice. J Neural Transm 32:37-43.

Lapin IP. 1980. Effect of kynurenine and quinolinic acid on the actions of convulsants in mice. Pharmacol Biochem Behav 13:17-20.

Lapin IP. 1982. Convulsant action of intracerebroventricularly administered L-kynurenine sulphate, quinolinic acid and of derivatives of succinic acid, and effects of amino acids, structure-activity relationships. Neuropharmacology 21:1227-1233.

Leboyer M, Philippe A, Bouvard M, Guilloud-Bataille M, Bondoux D, Tabuteau F, Feingold J, Mouren-Simeoni MC, Launay JM. 1999. Whole blood serotonin and plasma beta-endorphin in autistic probands and their first-degree relatives. Biol Psychiatr 45(2):158-163. 
Lebrand C, Cases O, Adelbrecht C, Doye A, Alvarez C, Mestikawy SE, Seif I, Gaspar, P. 1996. Transient uptake and storage of serotonin in developing thalamic neurons. Neuron 17:823-835.

Louw D, Sutherland GB, Glavin GB, Girvin J. 1989. A study of monoamine metabolism in human epilepsy. Can J Neurol Sci 16:394397.

Leventhal BL, Cook EH Jr, Morford M, Ravitz A, Freedman DX. 1990. Relationships of whole blood serotonin and plasma norepinephrine within families. J Autism Dev Disorders 20(4):499-511.

Mamounas LA, Altar CA, Blue ME, et al. 2000. BDNF promotes the regenerative sprouting, but not survival, of injured serotonergic axons in the adult rat brain. J Neurosci 20:771-782.

Munn DH, Zhou M, Attwood JT, Bondarev I, Conway SJ, Marshall B, Brown C, Mellor AL. 1998. Inhibition of $\mathrm{T}$ cell proleiferation by macrophage tryptophan catabolism. Science 281:1191-1193.

Muzik O, Chugani DC, Chakraborty P, Mangner T, Chugani HT. 1997. Analysis of [C-11]alpha-methyl-tryptophan kinetics for the estimation of serotonin synthesis rate in vivo. J Cerebr Blood Flow Metab 17(6):659-669.

Nabi R, Serajee FJ, Chugani DC, Zhong H, Huq AH. 2004. Association of tryptophan 2,3 dioxygenase gene polymorphism with autism. Am J Med Genet B 125(1): 63-68.

Natsume J, Kumakura Y, Bernasconi N, Soucy JP, Nakai A, Rosa P, Fedi M, Dubeau F, Andermann F, Lisbona R, Bernasconi A, Diksic M. 2003. Alpha-[11C] methyl-L-tryptophan and glucose metabolism in patients with temporal lobe epilepsy. Neurology 60:756-761.

Osterheld-Haas MC, Vander Loos H, Hornung JP. 1994. Monoaminergic afferents to cortex modulate structural plasticity in the barrelfield of the mouse. Brain Res Dev Brain Res 77(2):189-202.

Parent JM. 2002. The role of seizure-induced neurogenesis in epileptogenesis and brain repair. Epilepsy Res. 50:179-189.

Perkins MN, Stone TW. 1982. An iontophoretic investigation of the actions of convulsant kynurenines and their interaction with endogenous excitant quinolinic acid. Brain Res 247:184-187.

Perkins MN, Stone TW. 1983. Pharmacology and regional variation of quinolinic acid-evoked excitations in rat central nervous system (CNS). J Pharmacol Exp Ther 226:551-557.

Persico AM, Militerni R, Bravaccio C, Schneider C, Melmed R, Conciatori M, Damiani V, Baldi A, Keller F. 2000. Lack of association between serotonin transporter gene promoter variants and autistic disorder in two ethnically distinct samples. Am J Med Genet 7 96:123127.

Persico AM, Pascucci T, Puglisi-Allegra S, Militerni R, Bravaccio C, Schneider C, Melmed R, Trillo S, Montecchi F, Palermo M, Rabinowitz D, Reichelt KL, Conciatori $M$, Marino R, Keller F. 2002. Serotonin transporter gene promoter variants do not explain the hyperserotoninemia in autistic children. Mol Psychiatr 7(7):95-800.

Pintor M, Mefford IN, Hutter I, et al. 1990. The levels of biogenic amines, their metabolites and tyrosine hydroxylase in the human epileptic temporal cortex. Synapse 5:152-156.

Piven J, Palmer P. 1999. Psychiatric disorder and the broad autism phenotype: evidence from a family study of multiple-incidence autism families. Am J Psychiat 56(4):557-563.

Rosen GD, Burstein D, Galaburda AM. 2000. Changes in efferent and afferent connectivity in rats with induced cerebrocortical microgyria. J Comp Neurol 418:423-440.

Saito K, Nowak TS Jr, Suyama K, Quearry BJ, Saito M, Crowley JS, Markey SP, Heyes MP. 1993. Kynurenine pathway enzymes in brain Responses to ischemic brain injury versus systemic immune activation. J Neurochem 61: 2061-2070.

Salichon N, Gaspar P, Upton AL, Picaud S, Hanoun N, Hamon M, De Maeyer E, Murphy DL, Mossner R, Lesch KP, Hen R, Seif I. 2001. Excessive activation of serotonin (5HT) 1B receptors disrupts the formation of sensory maps in monoamine oxidase a and 5-ht transporter knockout mice. J Neurosci 21(3):884-896.
Schain RJ, Freedman DX. 1961. Studies on 5-hydroxyindole metabolism in autistic and other mentally retarded children. Disabil Rehabil 58:315-320.

Seldon HL. 1981a. Structure of human auditor cortex. I. Cytoarchitectonics and dendritic distributions. Brain Res 229:277-294.

Seldon HL. 1981b. Structure of human auditory cortex. II. Axon distributions and morphological correlates of speech perception. Brain Res 229:295-310.

Seldon HL. 1982. Structure of human auditory cortex. III. Statistical analysis of dendritic trees. Brain Res 249:211-221.

Scharfman HE, Ofer A. 1997. Pretreatment with L-kynurenine, the precursor to the excitatory amino acid antagonist kynurenic acid, suppresses epileptiform activity in combined entorhina/hippocampal slices. Neurosci Lett 224:115-118.

Suzuki S, Tone S, Takikawa O, Kubo T, Kohno I, Minatogawa Y. 2001. Expression of indoleamine 2,3-dioxygenase and tryptophan 2,3-dioxygenase in early concepti. Biochem J 355:425-429.

Teskey GC, Radford KS, Seif I, Dyck RH. 2004. $\mathrm{MAO}_{\mathrm{A}}$ knockout mice are more susceptible to seizures but show reduced epileptogenesis. Epilepsy Res 59:25-34.

Toczek MT, Carson RE, Lang L, Ma Y, Spanaki MV, Der MG, Fazilat S, Kopylev L, Herscovitch $\mathrm{P}$, Eckelman WC, Theodore WH. 2003. PET imaging of 5-HT1A receptor binding in patients with temporal lobe epilepsy. Neurology 60:749-756.

Trottier S, Evrard B, Vignal JP, Scarabin JM, Chauvel P. 1996. The serotonergic innervation of the cerebral cortex in man and its changes in focal cortical dysplasia. Epilepsy Res 25:79106.

Vezzani A, Ungerstedt U, French ED, Schwartz R. 1985. In vivo brain dialysis of amino acids and simultaneous EEG measurements following intrahippocampal quinolinic acid injections: evidence for a dissociation between neurochemical changes and seizures. J Neurchem 45:335-344. 